\title{
Beyond the Structure of Research: Image and Intuition
}

\section{Rafif Hakiem}

University of East Anglia, UK; King Saud University, Saudi Arabia

\section{Discipline}

Education [D2]

\section{Sub-discipline}

Learning Theories [SD-Edu-10]

\section{Academic Level}

Advanced Undergraduate

\section{Contributor Biography}

Rafif Hakiem completed at her PhD in education at the University of East Anglia (UK) in 2016. After several years of working with young children, she pursued an academic career and is a lecturer in curriculum and instruction, art education, at King Saud University, Saudi Arabia. She also holds a master's degree in general curriculum and instruction from King Saud University. Her $\mathrm{PhD}$ research began with an investigation of an art education teaching program in Saudi Arabia, broadening into a more intuitive and sociologically relevant study which investigates how participatory arts-based activities can shape research questions as well as teaching and learning practices. 


\section{Abstract}

Using my own practice as a researcher, this case seeks to demonstrate how the use of participatory arts-based methods is not just a way to collect data or answer predefined thesis questions, but can actually shape research questions and theses in ways one may not have initially considered. Initially, my $\mathrm{PhD}$ research focused primarily on the teacher-training program at one of the larger universities in Saudi Arabia, and the use of participatory visual arts-based activities helped in investigating and identifying learner experiences not easily put into words. As a result of this action-oriented practice, my research broadened from a conventional investigation toward a more intuitive and sociological-relevant study, and I found that arts-based participatory activities allowed participants to access different parts of consciousness. After reviewing different research methods, I chose to use participatory methods (specifically, image-based tasks given to participants) as a particularly democratic approach to research, one that views participants as direct agents, not objects. This inclusivity enables greater depth of participant involvement in the research process. Further to this, my study considers how these participatory methods connect people and may facilitate an empathy which can lead to more profound connections, despite individual differences.

\section{Learning Outcomes}

By the end of this case, students should be able to

- Demonstrate understanding of the value of non-linguistic communication for bridging the power relations that exist between researcher and the participants

- Understand the role of arts-based methods in teaching and learning and increasing knowledge and confidence for learners 
- Distinguish the perspective of visual arts from an exclusive practice to an everyday experience

- Demonstrate understanding of the relationship between individual and social values and experience toward a social conscientization

- Construct arts-based investigations as part of shaping research questions and themes

\section{Project Overview and Context: Adopting Participatory Arts-Based Methods}

This case reports from my $\mathrm{PhD}$ research into the art education teacher-training program at one of the larger universities in Saudi Arabia, using participatory visual arts-based methods as the primary research approach. To undertake this study, it was necessary for me to talk to individual participants (undergraduates, student-teachers, and faculty) to learn about their views; thus, semistructured interviews and focus groups were the main methods used to collect data. When I was piloting my study, it seemed particularly important to use a personal approach (which participatory arts-based methods provide) to diminish the hierarchy between researcher and participants. In choosing this approach, I felt more confident about raising an authentic dialogue and empathetic engagement between the participants and myself as researcher. Of all the research methods employed, I chose to use one-to-one interview because it is a powerful interaction process between people that can generate deep understanding in both the interviewer and the respondent. As Norman Denzin and Yvonna Lincoln (2000) state, “interviews are not natural tools of data gathering but active interaction between two (or more) people leading to negotiated, contextually based results" (p. 646). Interviews therefore helped me to explore the personal and sensitive issues or morally ambiguous choices people make. In other words, interviews helped participants and myself to be part of a dynamic, embracing more empathetic approaches in interviewing as a research method. As a result, I was able to better understand the challenges participants faced 
within the teaching program. I found my research worked in a similar way to Anna Bagnoli and Andrew Clark's (2010) notion that the researcher acts as a facilitator, helping participants to communicate and effectively build projects via action-oriented practice. I found such an approach fosters a democratizing of art via interpersonal interactions, in this case within an educational environment but also potentially in a social setting.

It might be useful to consider this case in the context of existing qualitative research because participatory arts-based methods of research are seen as an evolving genre within qualitative research. In other words, it might be helpful to look at the theoretical basis of the implementation of this study as well as the participatory events. For me, as well as other researchers, it is important to consider the social as well as individual values in participatory practice. I used image-based activities (incorporated into the in-depth interviews and focus groups) as part of a process of extending dialogue with participants, as a means of evoking direct and substantive comments and responses with regard to their backgrounds and their studies within the field of art education. In turn, this authentic dialogue allows for the participants/learners to better understand the value of self-expression, openness, and genuine communication in terms of one's role as an artist (or art educator) and the connection between these issues and broader society (i.e., a social conscientization).

\section{Arts-Based Research Design and Methods}

My research collected data over 5 months of fieldwork, using qualitative methods including oneto-one interviews and focus groups involving participatory activities, direct observation, and the use of personal experience. Participants included 10 undergraduates in the art education degree program whom I interviewed one-to-one and focus groups with 13 student-teachers in the final 
year of the program. All student participants were studying on modules in pedagogy offered for the art education program, and I tried to find at least two undergraduates for each of the courses to compare perspectives. The collection of participants' views via focus groups was the second most important research method after interviews. Teaching practice takes place with groups of students assigned together to a local participating school; thus, the division of students into focus groups followed the same grouping as in the schools. I spoke also with a few faculty members to add to my own understanding about the teaching program.

As there is very little consideration given for the students' voices in the context of the teacher-training program, I felt it important to try to understand students' experience of changes to and issues within the program, as well as to consider the imbalance of power given my relatively privileged position as a lecturer. As a result, some interviews were concluded swiftly, but others required more time or a second session. In the interviews/discussions with participants, I employed four sets of tools/materials and participatory arts-based activities. The activities included a multiform set (partially represented, see Figures 1-7 in the Practicalities section) with visual prompts (for writing/drawing responses), graphs, scales, and images for discussion. The knowledge-based activities were concerned with institutional issues (within the teacher-training program) and were designed to reveal students' understanding of the changes that occurred in the program. The experience-based activities were more personal or reflective in nature, allowing participants to express some of their experiences and feelings as a student in the program.

After my fieldwork, I transcribed the recorded data and reflected on my field notes, exploring salient issues and recalling extra details. It is important to note here that in my notes I recorded the participants' gestures that accompanied their speech along with other non-linguistic expressions such as extended sounds, sighing, tears, and laughter. In this way, rough jotting 
became detailed recollections and reflection, expanding my notes with further reflections, analysis, and insights. To preserve as much sense of the participants words as fully possible, I transcribed the audio-recorded files into Arabic script and then transliterated into Roman script for the draft thesis.

As my primary focus was on interviewing and engaging focus groups, I considered observation to be of minor importance; ethnographic observation would have required more time and more extensive surveillance than was feasible for this study. Direct observation (in the educational setting) was, however, immediately available to me. The interview and focus group data enabled me, as Helen Simons (2009) states, to get to the core issue in the research more quickly and in greater depth as compared with other methods such as survey, observation, and a reliance on documents.

\section{The Value of Participatory Arts-Based Methods}

In undertaking research in the field, I have tried to go beyond the standard interview and expand the domain of investigation by adopting a creative approach, incorporating visual arts-based methods. Patricia Leavy (2009) promotes the notion of incorporating participatory arts-based methods into the research process, offering two points: "visual arts-based methods are necessarily participatory" (p. 227) and, addressing Donald Blumenfeld-Jones' view, participatory visual artsbased methods allow for incorporating visual art (i.e., images literally, physically) into the research.

Given that, as Bagnoli (2009) puts it, a "multiplicity of dimensions" (including the visual and sensory) governs our daily experience, it was important to acknowledge these within the investigation. As she indicates, interview is the standard method of data collection in most 
qualitative research, but one must recognize that the use of interviews privileges language over other non-linguistic communication and expression or dimensions of knowledge. Bagnoli acknowledges Elliot Eisner's position that not all knowledge is reducible to language. Consequently, she reveals that the primary advantage for non-linguistic dimensions in research is that it allows one to access and represent different levels of participants' experience.

Sally Eaves (2014) identifies arts-based research methods as a "process that uses the expressive qualities of form to convey meaning" (p. 149). This approach echoes Eisner's and Bagnoli's claims that arts-based research blurs discipline boundaries and expands understanding. Connections are forged, which promote empathetic participation in participants' lives and social values beyond the participatory event.

This is all part of a broad, holistic approach to research available through participatory and visual arts-based research methods. I found this approach encouraged lateral thinking (e.g., in indirect and creative ways) and non-standard responses by participants. This notion of "thinking outside the box" led Tom Barone and Eisner (2012) to suggest that artistic activity itself is often employed as part of arts-based research to illuminate and add to perspectives associated with activities such as these-activities which, for arts-based educational research (ABER), are inherently educational because ABER activities work to expand ongoing conversation about educational practice, as opposed to simply securing 'solid explanations and confident predictions' (p. 96), both of which traditionalists generally seek to secure.

In my research, I found that the adoption of an arts-based approach (in the interview and focus group contexts) facilitated participant expression. Carl Bagley and Ricardo Castro-Salazar (2012) consider the use of arts-based methods within educational research as legitimate in the 
context of existing qualitative research, "[setting] out its own methodological stall in order to stimulate debate and legitimize itself within the qualitative research paradigm” (p. 241). Thus, artsbased research can be seen as "an evolving methodological genre within the qualitative paradigm" (Bagley and Castro-Salazar, 2012).

If we consider the value of artistic activity in arts-based research, it is clear (and Barone and Eisner support this claim) that it can illuminate participants' perspectives and encourages ongoing conversations, as opposed to simply securing predictable explanations. As an example of this, when I interviewed a male colleague (by phone, due to social constraints because it is not possible for unrelated men and women to meet face-to-face), it began as a formal interview, on his terms. He himself conducts qualitative research by structured interviews; however, he acknowledged that my participatory methods were different, enabling more movement between points rather than merely a question-and-answer session as in a traditional interview.

Although Barone and Eisner see congruence in educational and aesthetic outcomes and treat them with parity, my own arts-based research would lead me to consider the former more significant than the latter, with aesthetic qualities of little or no consideration in evaluating participant data.

\section{Practicalities}

\section{Using Participatory Activities}

During my data collection, I found that direct questions appeared to be difficult for some undergraduates to answer because they knew very little about the infrastructure of the teaching program and because it is unusual for students to contribute to interviews with faculty members. Given these difficulties, I employed tools and activities that would engage the students and invite 
more open, reflective responses. It is important to note that the student sample was randomly chosen; however, the sample increased because interest in the research grew as students responded positively and found that they could voice their views and concerns in an authentic dialogue with a faculty member.

It was important that I did not let my position as a lecturer in the university affect the students' freedom to act naturally. I needed to balance the power of my position as a university member and as an insider researcher, for example, with the need to explain to them that I do not have a strong link with their lecturers or supervisors as I was in the college for a short period of time to conduct my fieldwork. My aim was to give participants the freedom to act naturally by eliminating any fear of their lecturers' and supervisors' views of their participation. In addition, I served coffee and biscuits to help break the ice and settle participants. It is important to note that the use of the materials/activities helped considerably in shifting the mood in which some arrived and helped engage them in discussion. Thus, this multi-form set- the tools/material/activities used with students—aided communication and were used because I felt they would arouse more interest and invite greater involvement in the process.

Indeed, the discussions lasted more than an hour, and all participants expressed their interest in an experience so different from the usual routine. This was their first experience of interactive learning tools within a one-to-one context (i.e., outside of class activities), and all reported finding it useful as well as enjoyable. One student said, "I had no idea the interview would be such an interesting discussion," and in the next meeting she came with her friend who asked whether she could join. Even though many expressed concerns about taking time for our interview, all ended up talking for more than 1 hour. One participant told me "I don't have time at all," but during our session she became so keen to talk about her concerns that she preferred to cancel a 
lecture to carry on the conversation, saying it was more useful than the lecture. When I tried to bring things to an end, suggesting we complete the discussion later, she was reluctant and wanted to carry on.

Thus, the visual art methods are a way of achieving non-hierarchical research practice while keeping ethics in the frame of reference. It is interesting to note the ways experience-based activities allowed participants to express ideas freely using their own words or images rather than the graphics, scales, and pointers provided in the knowledge-based activities. In other words, I found the experience-based activities resulted in greater freedom of imagination in responses, which nonetheless complement the knowledge-based activities and the data these provide.

In many ways, too, these methods aided my own critical thinking and research practices, in terms of generating new ways of interrogating and understanding not just the teacher-training program but broader socio-educational issues.

\section{Knowledge-Based Activities}

1. The first activity (Figure 1) asked students to consider their understanding of the National Council for Teacher Education (NCATE) standards which had been implemented in the teaching program. Using different colored stickers, students represented their awareness of these standards. The sticker colors operated as a code and as such were scaled, whereby red represented no appearance of the standards, blue represented limited appearance of standards, green represented some appearance of standards, and yellow represented considerable appearance, whereas white represented fully evident appearance of the standards. The value in activities such these (Figures 1 and 2) is not on generating expert 
knowledge, but expressing experimental knowledge, as Henk Slager (2009) suggests, in particular "attention to the unique, the qualitative, the particular, and the local" (p. 2).

Figure 1. Knowledge based activity about NCATE standards

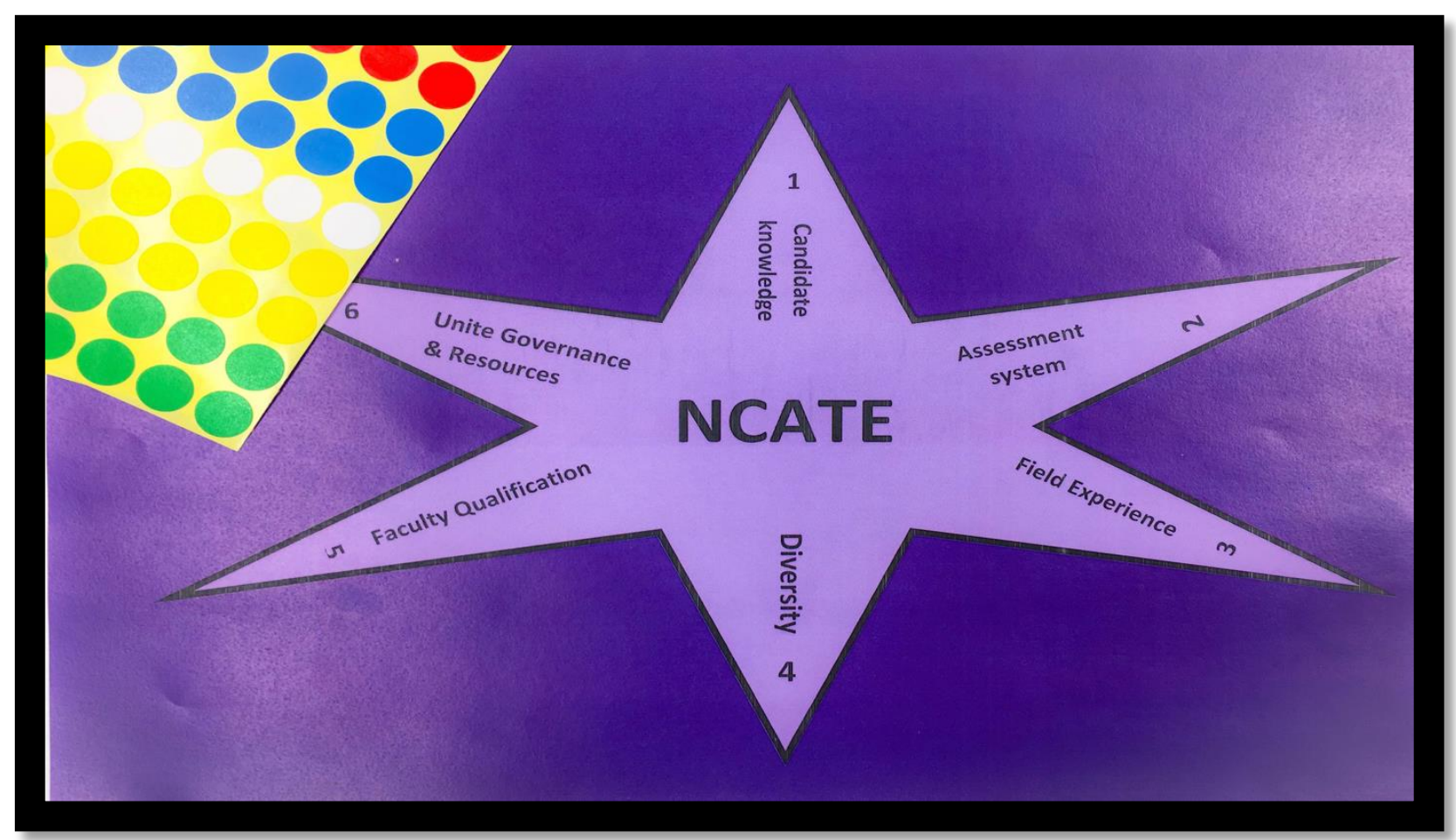

2. The second activity (Figure 2) focuses on the Conceptual Framework of the College of Education. I applied five criteria to labels of three sizes to represent the extent to which participants felt each criterion had influence in the teacher-training program (to a greater extent, a lesser extent, almost no extent). The students used these labels as part of our interview discussion, taking the issues within the criterion and applying them beyond the program to their own lives. 
Figure 2. Knowledge based activity about the influence of the Conceptual framework on the teaching program

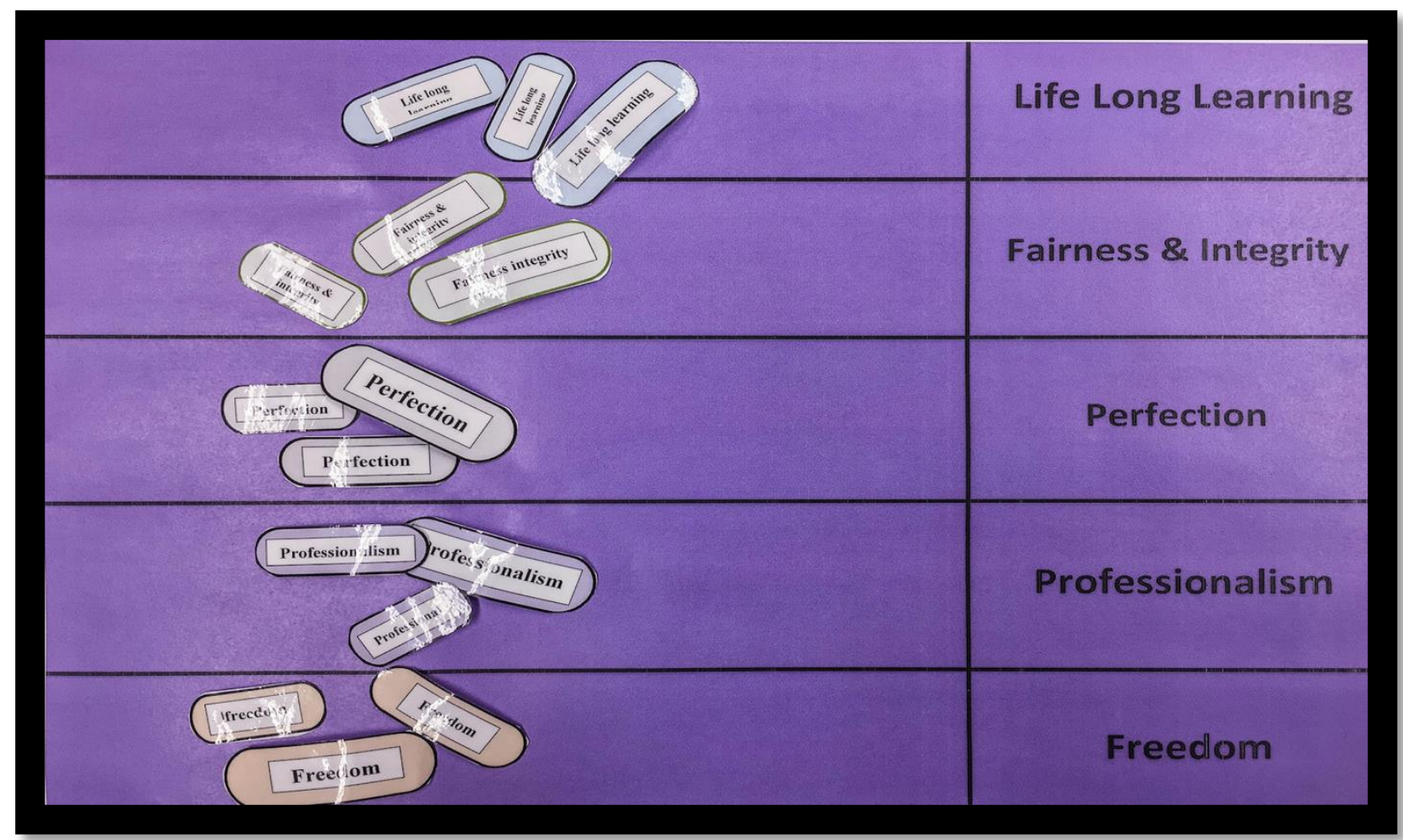

\section{Experience-Based Activities Employed in Research}

1. During discussion about the role of the student and teacher in the educational process, I used an image of a student asleep at a desk (Figure 3) to help participants articulate their feelings about being a learner in the teaching program. Rosalind Hurworth (2003) discusses the advantages of using photos within interviews: "we have seen that photo-interviewing in its various forms can be a particularly powerful tool for the researcher. It can challenge participants, provide nuances, trigger memories, lead to new perspectives and explanations, and help to avoid researcher misinterpretation" (p. 3). 
Figure 3. Experience based activity - image to prompt discussion

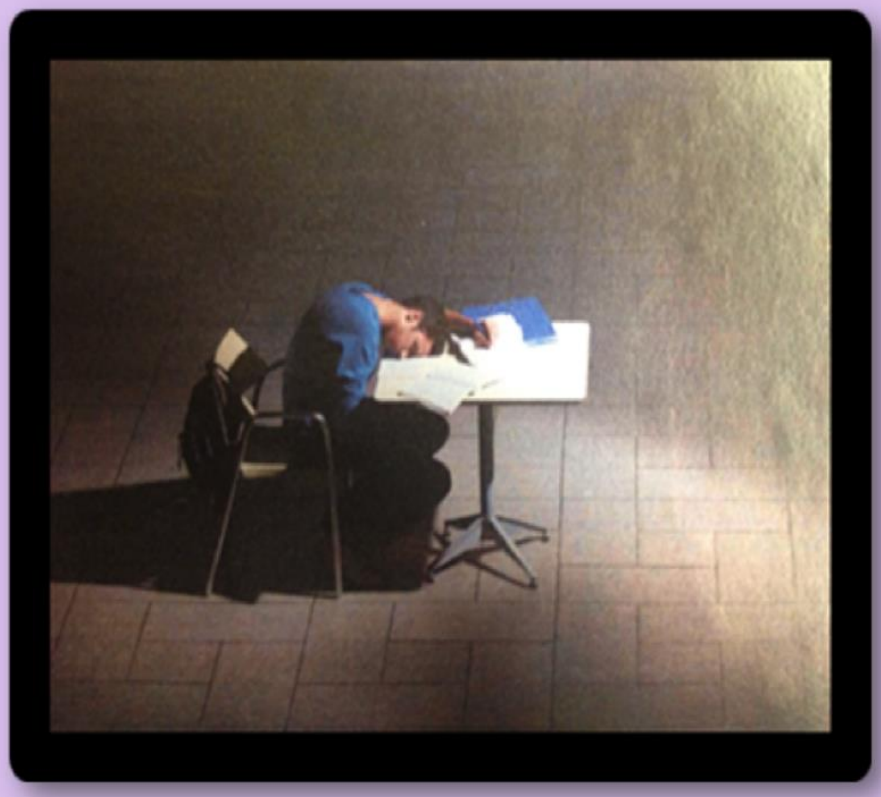

2. To enquire as to who students see as responsible for decisions which affect their day-today learning, this activity (Figure 4) asks students to use pens to mark who is responsible for the following: the timetable, the tutor, activities in and out of the class, module content, and the module goals or objectives. For these activities (Figures 4 and 5), I used two matrices developed from those used with primary school children by Sue Cox et al. (2003). They described the understanding that decision-making is the first step toward empowerment, which they demonstrated using a number of a visual practical activities, enabling children to put decision-making into context. They concluded that the skills and knowledge acquired from these experiences are not abstract, nor the resulting discussion theoretical, but real and useful for participants to apply in the wider world. 
Figure 4. Experience based activity about decision making within the teaching program

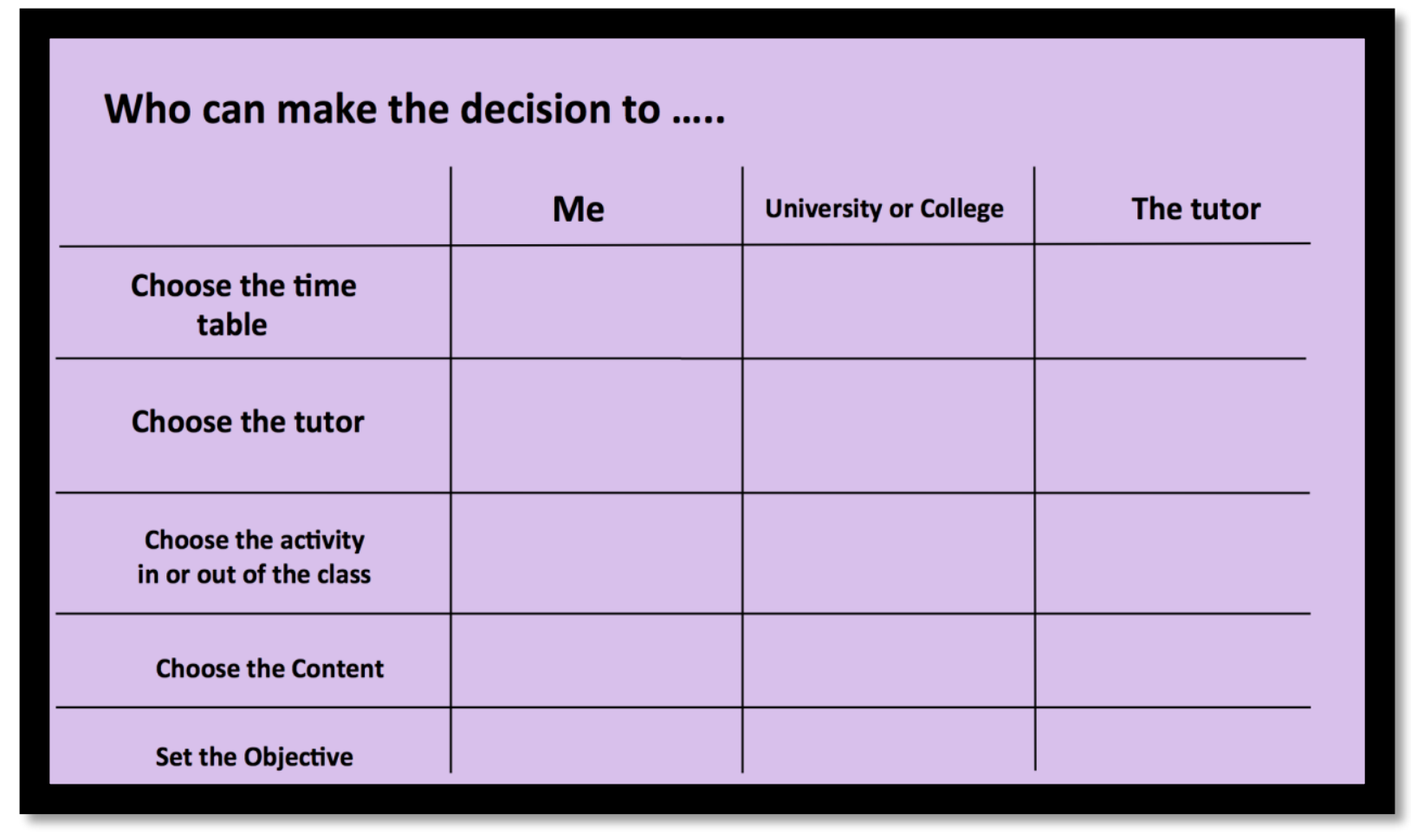

3. Similarly, this task (Figure 5) asks participants to place a mark, indicating to what extent they feel able to make decisions within modules, within the teacher-training program and also within university activities. 
Figure 5. Experience based activity about decision making with the teaching program

To what extent do you have the right to make decisions in :

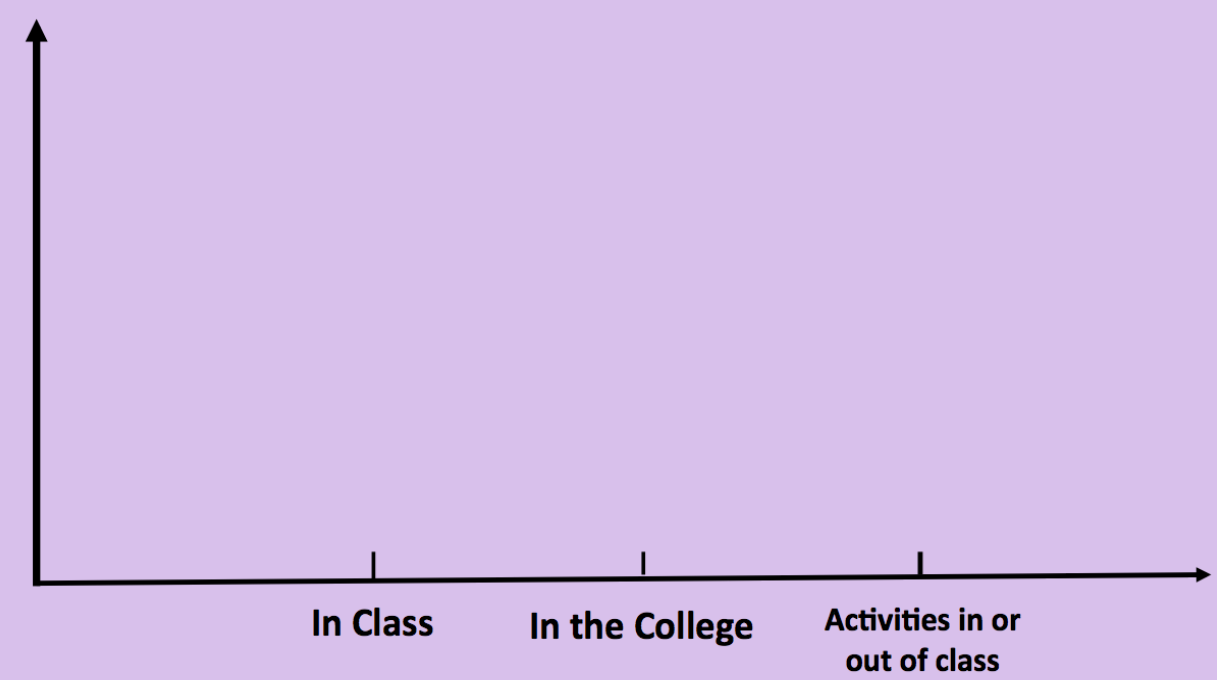

4. The self-portrait technique (Figure 6) asked participants to express their feelings about themselves as students in the teacher-training program by drawing an image to represent themselves. Bagnoli describes self-portrait as an arts-based project technique she employed for encouraging young people's reflexivity and getting them to think holistically about identity and life. 
Figure 6. Experience based activity inviting discussion about individual student experience

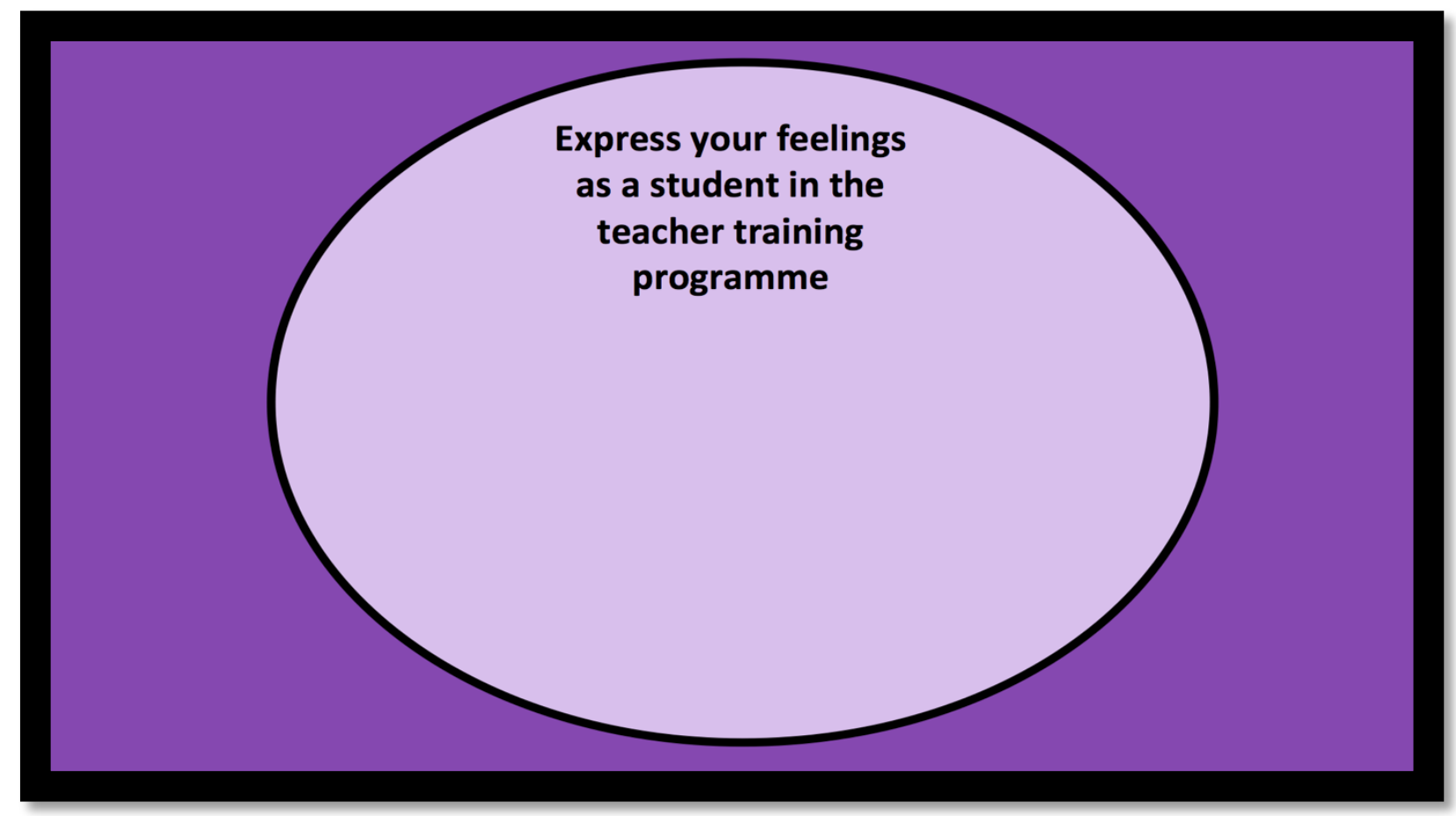

5. This activity (Figure 7) is related to the discussion concerning developments participants would like to see within the program. Participants could write/draw within the frame whatever they wanted in response to the issues related to this question. According to Bagnoli, in using visual methods as a tool, the aim is not only to assist with interviews as a kind of "add-on" but as an important method of eliciting and understanding experience in its own right. Thus, the technique evokes embodied experience and opens opportunities for deeper conversations about issues than does the traditional interview question-andanswer format within qualitative research. 
Figure 7. Experience based activity inviting ideas for changes to the teaching program

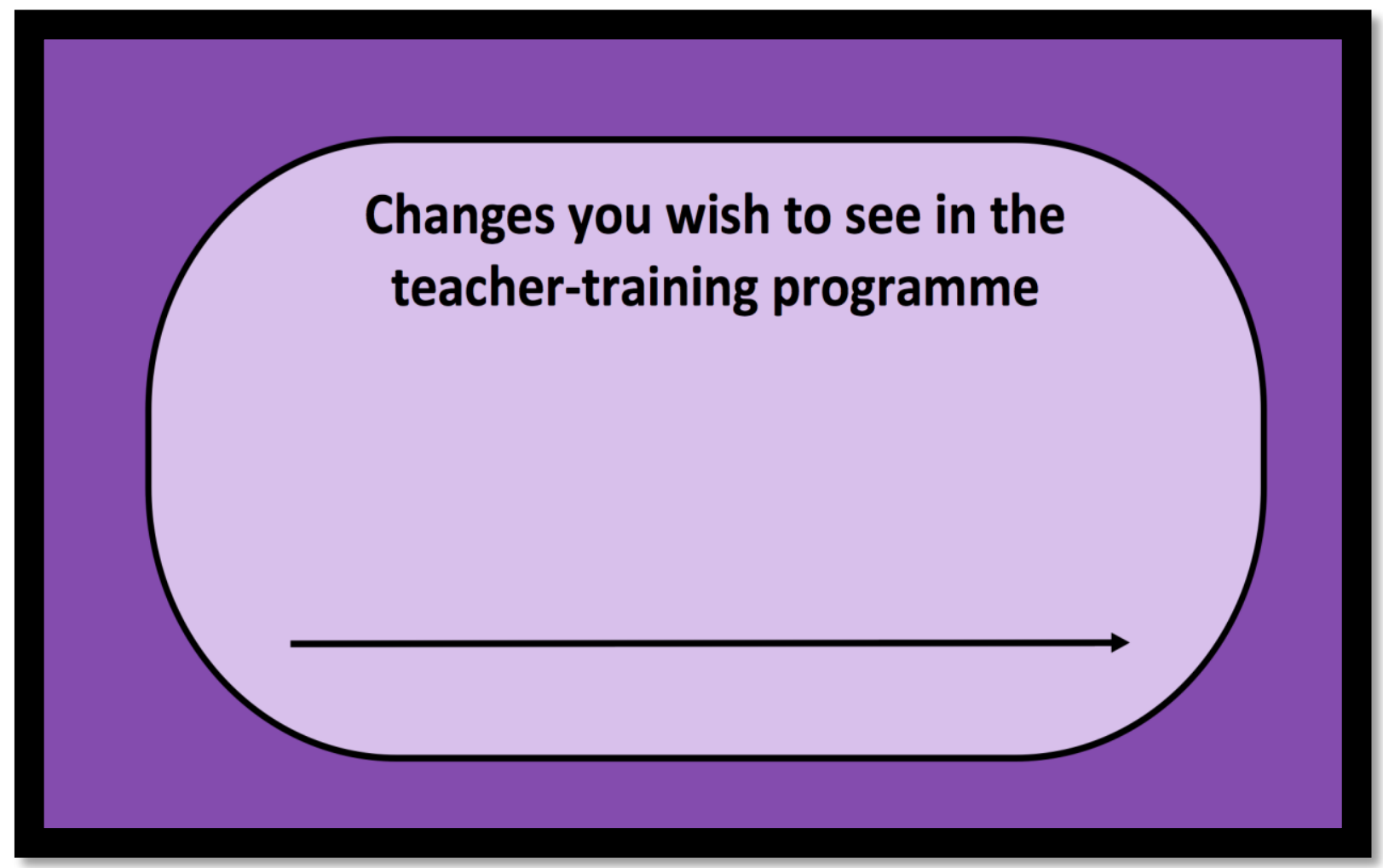

\section{Non-Linguistic Forms of Research and Method in Action}

When considering the incorporation of participatory arts-based methods into the research process, we are reminded that multiple dimensions (including the visual and sensory) govern our daily experience (Bagnoli, 2009), so for me it was important to acknowledge these within my investigation. Although interview is the standard method of data collection in most qualitative research, it cannot elicit every facet or view expressed by participants. In addition, the use of interviews privileges language over other non-linguistic communication and expression or dimensions of knowledge. Consequently, an advantage for non-linguistic communication in research is that it allows researchers to access and represent different levels (including the visceral 
and sensory) of participants' experience often captured as they express themselves through gesture and informal expression.

This corresponds to my own research, where I found the use of participatory activities helped in investigating and identifying layers of experiences not easily put into words. An example of how participatory methods can enable communication at different levels became clear when I showed one of the student participants a photograph of a student asleep (see Figure 3) at his desk; she responded, "hadi halatana" - an Arabic expression meaning "that is us!" When I asked her opinion about the teaching program, she shook her head and said, "There isn't any interest in-our subject at all."

The participatory methods also helped encourage full engagement and sharing of ideas between myself (as the researcher) and participants as well as enabling an immediate rapport. For example, one student expressed real pleasure at the freedom the interview gave her to discuss issues within the teaching program and when, during the conversation her phone rang and I asked whether she wished to answer, she responded emphatically, "No I do not, let us carry on our conversation." I found the methods allowed participants to express themselves honestly and openly, and one student concluded our discussion saying, "This is the beginning of change and I am really glad to meet you."

So it may be said that the use of images or arts-based activities in research offers a number of benefits. This is evidenced not only by the examples here but also by literature that shows the value of engaging participants in the core of the research. For example, Sara Kindon, Rachel Pain, and Mike Kesby (2007) note that "participatory" is not merely a type of research method, but rather the depth of involvement by participants in the whole research process. Thus, it allows 
participants to access different parts of human consciousness, paying attention to their own reality in various ways:

- The arts-based methods are a way of achieving non-hierarchical research practices, allowing participants to provide as much information as they wish (Patton, 2002).

- These methods can provide flexibility and spontaneity during the interviewing process.

- Each participant can become an advocate and partner in the study, helping to explore experiences as well as others' opinions.

Researchers may find that arts-based participatory activities allow connections on different levels and facilitate understanding, which can lead to profound connections, despite individual differences. It is a method that helped me in 'connecting people on emotional and visceral levels (and) artistic forms of representation facilitate empathy, which is a necessary pre-condition for . . . building coalitions/community across differences' (Leavy, 2009, p. 14).

\section{Practical Issues Within Arts-Based Research}

During data collection, it is important to bear in mind what you will do with the data because making sense of qualitative data is a delicate task and requires a meticulous attitude. I used audiorecording in my own research, although I would have liked to video the interviews, but this is not culturally acceptable for female participants. I used rough notes and jottings going through the audio-recordings, expanding on these so that they became detailed recollections and reflections. I frequently re-read these notes to gain contextual understanding, expanding them with further reflections, analysis, explanations, and insights. 
After completing my fieldwork, I immediately began to transcribe, in handwritten form, all the recorded data (interview and focus group) using pen and paper, to preserve as much sense of the participants' words as possible. Accordingly, handwriting as a method helped to integrate analysis with the process of transcription.

\section{Practical Lessons Learned}

The following are some practical tips from lessons I learned through the course of my research:

1. Be aware that it is not unusual for the methodology focus to shift or alter as your research develops; therefore, you should be willing to modify any research plans in light of new discoveries from your participants. I identified unexpected themes and ideas that emerged as my data collection matured and found an alternative position out of my research, broadening from a conventional investigation (of the teacher-training program) toward a more intuitive, sociologically relevant study.

2. When designing arts-based activities, think carefully about how they will help you to forge connections with your participants and get the most from their participation; you will need to consider the following:

a. To what extent these activities can help discussion so that participant reflexivity can develop and add depth to the research. I was also pleased with the ways visual artsbased activities fostered self-reflexivity in my research.

b. Well-designed activities can make a difference to the enthusiasm of the participants; one of my participants said "let's have more of these games!" when playing with different activities. Overall, participants seemed to find our discussion and activities a 
pleasant experience. This seemed especially true when I listened more and let the participants speak while engaging with the visual arts-based activities.

3. Planning and designing the activities requires time, so it is a good idea to avoid setting narrow time parameters for the activities; no matter how you plan to use the activities, the participants may have their own ideas and ways of finding answers.

4. Do not rely solely on your own memory of events; make sure you write notes to which you can refer during data analysis, ideally audio or video recording what is said and reflecting on or including gestures or mannerisms (e.g., pauses, sighs, laughter)—all of which may be useful when analyzing the data and writing up your research report.

5. If interviewing participants on more than one occasion, it is beneficial to offer them an account of the previous discussion; in my case, I showed them the synopsis and said, "This is what came out of our meeting, would you like to change anything?" This question acted as a catalyst to reactivate the discussion.

\section{From Methods to Practice and Advocacy}

Beyond simply knowing the proper research and design of professional social research, an awareness and application of ethical principles are required. I, as a researcher, was keen to create a relationship in which participants felt comfortable taking part, keeping ethics in the frame of reference. The potential existed for boundaries to be crossed by participants in revealing their feelings about individuals in or out of the program, or potential harm may have resulted from participants' "complaints" about the program. Some were concerned as to whether other lecturers might hear of any negative comments they may have made during the interview. Thus, this 
relationship requires considerable application of ethical values, and do no harm was the basis of my consideration when planning my research.

As arts-based methods are immersive and revealing, it was important to not only build trust but also maintain professional boundaries. Nonetheless, the activities helped remove the conventional power dynamic between me and my participants, raising an authentic dialogue and empathetic engagement.

Studies have shown that participatory methods are unlike most other techniques because the emphasis is on the importance of harnessing the non-academic, local knowledge (or experience) of the people themselves to act upon and solve local problems. Richard Bowd, Alpaslan Özerdem, and Derese Getachew Kassa (2010) talk about the transference of power from the elite, or those who control knowledge, to people who do not normally assume any decisionmaking roles, indeed who do not usually have a voice. Although the young women who participated in my research may not be able to exactly emulate the kind of transference of power that Bowd and colleagues speak of, most showed increasing awareness of, and for some increased confidence in, articulating their ideas, or even their needs, as students in the teaching program.

In some cases, arts-based practice using visual media has enabled a transformation in individual (and collective/cultural) identity. We see this shift also in some teaching practices (and even the educational curriculum in some Western institutions) as well as academic research that have begun to utilize visual and social media as a learning tool, using Twitter or Facebook, or Blackboard for group discussion. It is a language most people, particularly students, speak daily outside the classroom. 
Bagley and Castro-Salazar argue that using arts-based research has the potential to speak for and engender understanding among a wide and diversified audience beyond the confines of the academy; particularly how the fusion of the arts with qualitative research has critical potential in terms of representation. People can not only be moved to express themselves more openly, but it can motivate someone toward action.

In many ways, these methods aided my critical thinking, as well as research practices during my investigative work, in terms of generating new ways of interrogating and understanding not only the teacher-training program in which I work but also the extent of my comprehension of art education issues in Saudi society.

\section{Conclusion: Image and Intuition}

During my research, I found that a lack of knowledge and choice about their training as teachers was a concern for many of my research participants, and the arts-based activities I provided allowed the students and student-teachers to gain a greater understanding of what occurs in their learning/training. This then improved the learning experience for students, as well as learning outcomes. Such activities provided an acquisition of knowledge and a broader understanding of the aims and practices of the program in which they were enrolled, which makes for more informed, well-rounded learners. In any case, the activities made it possible for them to discuss issues within the program which challenged them, and as such, they are valuable both in their own right (allowing participants to express themselves) and for raising student participant awareness and confidence.

Added to that, participatory arts-based research offers researchers inventive routes to add to knowledge beyond individual experience, allowing researchers to discern patterns of thinking 
and attitudes that may be seen as individual, in a particular environment or context, but also representative of broader thinking, including a social or collective dimension. For instance, my research has helped in terms of using the results to advocate with regard to the issues which the interviewees and I share, in this case concerning the teaching program and beyond the university, to society at large.

Indeed, the stories produced by the various visual methods not only revealed issues within the teacher-training program, but they also suggested that the educational institutions may be seen as a microcosm of larger society (in this case, in their attitude toward art and art education). Thus, the use of participatory arts-based methods is not just a way for researchers to collect data or answer predefined thesis questions, but can actually shape questions and theses in ways they may not have initially considered.

Finally, the use of participatory arts-based methods can provide unexpected benefits as well; in my case, these methods aided not only my understanding of my research participants but also my own growth as a researcher and educator, because using these kind of methods helped a great deal in developing my own perspective on the purpose of art in the context of education.

\section{Exercises and Discussion Questions}

1. This study relies on bridging the power relations that exist between researcher and participants. What are the implications of breaching hierarchies within a classroom context?

2. In this case, there was a depth of involvement in the whole research process for myself as researcher as well as for participants. Why might this level of involvement or commitment be an issue for another researcher? 
3. What are the advantages of using of non-linguistic communication within interview and focus groups? What criticisms can you think of regarding this approach?

4. List ways in which arts-based research and activities can promote individual awareness and understanding of issues, building greater confidence in and outside the classroom.

5. The methods for interview and focus groups used in this case connect people and facilitate empathy; how important is this in social research? Explain your answer.

\section{Further Reading}

Bryman, A. (2012). Social research methods (4th ed.). New York, NY: Oxford University Press.

Cahnmann-Taylor, M. (2008). Arts-based research: Histories and new directions. In M. Cahnmann-Taylor \& R. Siegesmund (Eds.), Arts-based research in education: Foundations of practice (pp. 3-15). London, England: Routledge.

Clark, A., Holland, C., Katz, J., \& Peace, S. (2009). Learning to see: Lessons from a participatory observation project in public spaces. International Journal of Social Research Methodology, $12,345-360$.

Rubin, H., \& Rubin, I. (2012). Qualitative interviewing: The art of hearing the data. London, England: SAGE. 


\section{References}

Bagley, C., \& Castro-Salazar, R. (2012). Critical arts-based research in education: Performing undocumented histories. British Educational Research Journal, 38, 239-260.

Bagnoli, A. (2009). Beyond the standard interview: The use of graphic elicitation and arts-based methods. Qualitative Research, 9, 547-570.

Bagnoli, A., \& Clark, A. (2010). Focus groups with young people: A participatory approach to research planning. Journal of Youth Studies, 13, 101-119.

Barone, T., \& Eisner, E. (2012). Art-based educational research. Thousand Oaks, CA: SAGE.

Bowd, R., Özerdem, A., \& Kassa, D. (2010). Introduction to Part I: Participatory research methodologies: Development and post-disaster/conflict reconstruction. In A. Özerdem \& R. Bowd (Eds.), Participatory research methodologies: Development and post-disaster/conflict reconstruction (pp. 21-27). Aldershot, UK: Ashgate Publishing.

Cox, S., Robinson-Pant, A., Elliott, B., Jarvis, D., Lawes, S., Millner, E., \& Taylor, T. (2003). Empowering children through visual communication. Norwich, UK: School of Education and Professional Development, University of East Anglia.

Denzin, N., \& Lincoln, Y. (2000). Handbook of qualitative research. Thousand Oaks, CA: SAGE.

Eaves, S. (2014). From art for art sake to art as means of knowing: A rationale for advancing artbased methods in research, practice and pedagogy. The Electronic Journal of Business Research Methods, 12, 147-160. 
Hurworth, R. (2003). Photo-interviewing for research (Current Issues in Social research UPDATE). Retrieved from sru.soc.surrey.ac.uk/SRU40.html

Kindon, S., Pain, R., \& Kesby, M. (2007). Participatory action research approaches and methods: Connecting people, participation and place. London, England: Routledge.

Leavy, P. (2009). Method meets art: Arts-based research practice. London, England: The Guilford Press.

Patton, M. (2002). Qualitative research \& evaluation methods (3rd ed.). London, England: SAGE.

Simons, H. (2009). Case study research in practice. London, England: SAGE.

Slager, H. (2009). Nameless science. Art \& Research: Current Issues in A Journal of Ideas, $\begin{array}{lllll}\text { Contexts and } & \text { Methods, } & \text { 2(2). } & \text { Retrieved }\end{array}$ http://www.artandresearch.org.uk/v2n2/pdfs/slager.pdf 